University of Nebraska - Lincoln

DigitalCommons@University of Nebraska - Lincoln

November 1998

\title{
SCALES 2: COMPUTER PROGRAM TO CONVERT AMONG DEVELOPMENTAL STAGE SCALES FOR CORN AND SMALL GRAINS
}

\author{
Dorothy M. Harrell \\ University of Nebraska-Lincoln, dharrell2@unl.edu \\ Wallace Wilhelm \\ University of Nebraska-Lincoln, wwilhelm1@unl.edu \\ Gregory S. McMaster \\ USDA-ARS, greg.mcmaster@ars.usda.gov
}

Follow this and additional works at: https://digitalcommons.unl.edu/usdaarsfacpub

Part of the Agricultural Science Commons

\begin{abstract}
Harrell, Dorothy M.; Wilhelm, Wallace; and McMaster, Gregory S., "SCALES 2: COMPUTER PROGRAM TO CONVERT AMONG DEVELOPMENTAL STAGE SCALES FOR CORN AND SMALL GRAINS" (1998). Publications from USDA-ARS / UNL Faculty. 80.

https://digitalcommons.unl.edu/usdaarsfacpub/80
\end{abstract}

This Article is brought to you for free and open access by the U.S. Department of Agriculture: Agricultural Research Service, Lincoln, Nebraska at DigitalCommons@University of Nebraska - Lincoln. It has been accepted for inclusion in Publications from USDA-ARS / UNL Faculty by an authorized administrator of DigitalCommons@University of Nebraska - Lincoln. 


\section{SCALES 2: COMPUTER PROGRAM TO CONVERT AMONG DEVELOPMENTAL STAGE SCALES FOR CORN AND SMALL GRAINS}

\author{
Dorothy M. Harrell, ${ }^{*}$ Wallace W. Wilhelm, \\ and Gregory S. McMaster
}

\begin{abstract}
Producers and agronomists need crop developmental scales that are easy to use, universally accepted, and accurate. Development of such a scale requires correlation of stages among scales currently in use and correlation of developmental patterns among crops. A computer program for converting among staging systems is a useful tool in developing new staging systems with wider applicability. The BBCH scale (BASF-Bayer-Ciba-Geigy-Hoechst) has been proposed as a prototype of a universal scale. We have added the BBCH scale to our scale conversion program for wheat (Triticum aestivum L.) and developed a similar conversion program for corn (Zea mays $\mathbf{L}$.), based on correlations reported in the literature. SCALES 2 provides a tool to translate among several widely used scales for corn and small-grain development, and can be used to develop familiarity with the various scales.
\end{abstract}

$\mathrm{P}$ articipants in the Assessing Plant Growth Staging Needs for Crop Management symposium at the 1994 Tri-Society (ASA, CSSA, and SSSA) meetings in Seattle, WA, discussed the need for identifying, developing, and using meaningful plant developmental scales in scientific papers and technical reports and for applying routine crop management. Producers, scientists, and other industry specialists need developmental scales that are easy to use, are universally accepted, and accurately describe the development of the plant. A general scale, applicable to all crop and weed species, could have the added advantages of standardizing computer use and storage of phenological information and facilitating comparisons among species, even those without specific scales. Such a single developmental scale for all crops and weeds may not be possible, however, especially if it is to meet the criteria of accuracy and ease of use. At the 1994 meetings, the BBCH scale developed in Europe (Lancashire et al., 1991) was presented as a prototype of a universal scale. Subsequently, a CSSA ad hoc committee ${ }^{1}$ was formed to begin standardizing presentation of growth stage information in CSSA publications and to investigate the potential and practicality

${ }^{1}$ C392.1. Ad hoc Committee on Standardizing Growth Stages for CSSA Publications. Albert D. Flowerday (Univ. of NebraskaLincoln) and Albert B. Frank (North Dakota State Univ., Fargo), co-chairs.

D.M. Harrell, Dep. of Agronomy, and W.W. Wilhelm, USDA-ARS and Dep. of Agronomy, Univ. of Nebraska, Lincoln, NE 68583; G.S. McMaster, USDA-ARS, Great Plains Systems Res., P.O. Box E, Fort Collins, CO 80522. Joint contribution of the USDA-ARS and the Nebraska Agric. Res. Div. Published as Journal Series no. 11986, Agric. Res. Div., Univ. of Nebraska. Received 1 Aug. 1997. *Corresponding author (dharrell@unlinfo.unl.edu).

Published in Agron. J. 90:235-238 (1998). of developing a universal phenological scale for crop and weed species.

Development of a scale applicable to multiple plant species requires correlation of developmental patterns among the crops as well as correlation of stages used by developmental scales already in use for each crop. Even if the goal of a single, universal scale is ultimately unattainable, scale correlation is important to achieving the initial goal of standardizing developmental scales in scientific reporting and crop management and to aid communication among users during the transition in scales. The ad hoc committee has proposed that all papers in CSSA publications include a description of the crop in terms of a citable scale.

Previously, Harrell et al. (1993) developed a Fortran program called SCALES that converted among three commonly used developmental stage scales for wheat: the Feekes (Large, 1954), Haun (Haun, 1973), and Zadoks-Chang-Konzak (Zadoks et al., 1974) developmental scales. To help address the needs of the ad hoc committee, SCALES was expanded to include the $\mathrm{BBCH}$ developmental scale for small grains and conversion between the Hanway (Ritchie et al., 1986) and $\mathrm{BBCH}$ developmental scales for corn. The Hanway scale is the main developmental scale currently used for corn. The correlations are based primarily on tables and stage descriptions presented by Bauer et al. (1983) and Lancashire et al. (1991). The expanded version of our program is called SCALES 2.

The purpose of SCALES 2 is to enhance communication among scientists, students, and practitioners by providing a tool that allows those familiar with one developmental scale to quickly and accurately describe the plant in terms of a scale with which others are more familiar and that also facilitates learning new scales. In addition, the code is designed to be incorporated into simulation models.

\section{Program Description}

SCALES 2 consists of two components: SGSCALES for small grains converts among the $\mathrm{BBCH}, \mathrm{ZCK}$ ( $\mathrm{Za}-$ doks-Chang-Konzak), Feekes, and Haun scales, and CSCALES for corn converts between the $\mathrm{BBCH}$ and Hanway scales. SGSCALES and CSCALES are written in Fortran 77. The programs are structured to function as a dichotomous key, presenting to the user a series of questions about plant characteristics and/or the stage of development in the known scale. The information provided is processed and the developmental stage in the unknown scales is output, along with a verbal description of plant characteristics at that stage of development. SCALES 2 retains as much information as each scale permits. Three codes are used concurrently on the $\mathrm{BBCH}$ and ZCK scales. The first code (10-19) describes leaf development; the second code (20-29), used for SGSCALES only, describes tillering; the last code (3099) describes later vegetative and reproductive development. Feekes values are converted to decimal numbers (e.g., 10.5.1 becomes 10.51).

Abbreviations: ZCK, Zadoks-Chang-Konzak. 


\section{Assumptions and Limitations}

The programs assume that user-supplied information is correct. Although error checking rejects inputs outside reasonable bounds, bounds are liberal, to allow the programs to be applied to unusual growing conditions without rejecting the unusual inputs as errors. If the user enters conflicting information, the results may not be reliable. For example, if the user enters a very low Haun value but indicates that the plant is in anthesis, SGSCALES accepts this as accurate. If the user indicates that a corn plant has three leaves and six detectable nodes (as might occur from hail or frost damage), CSCALES incorrectly designates the plant as in the three-leaf stage. The user should instead respond to the prompt requesting the number of leaves produced by the plant with an estimate of the total number of leaves produced rather than relying on the number of visible leaves.

Stage numbers may be skipped. This may result from inaccurate information (e.g., if the user indicates in SGSCALES that the pseudostem is erect prior to tillering being completed, the Feekes value will skip from 2 to 4) or because the plant reaches another milestone first: in CSCALES, for example, if pollen shed begins before the tassel emerges completely, the $\mathrm{BBCH}$ value will skip from 55 to 63 , and the VT (tasseling) stage will be skipped on the Hanway scale.

Some interpretation of the five scales was necessary in developing the program. In small grains, for example, the Feekes scale value of 3 corresponds to "tillers formed...." (Large, 1954). This was interpreted to mean that tiller development was complete. Also, Feekes Stage 7 is described as "second node of stem formed; next to last leaf just visible...." If these events occur at different times, SCALES 2 assumes that Feekes Stage 7 is reached when the second node is visible. Other assumptions are evident from the scale comparisons shown in Tables 1 and 2.

\section{Results and Discussion}

Corresponding values used by SCALES 2 for the $\mathrm{BBCH}$ and Hanway scales for corn and the BBCH, ZCK, Feekes, and Haun scales for small grains are shown in Tables 1 and 2, respectively. The table for small grains is very similar to the scale correlation table of Bauer et al. (1983). Verbal stage descriptions in the tables and in the program output are based primarily on the descriptions of the $\mathrm{BBCH}$ scale, with additional descriptions added for important landmarks on other scales. Although not principal growth stages on the $\mathrm{BBCH}$ scale, flag leaf extension and spike elongation are shown as separate major divisions in SGSCALES because they represent whole units on the Haun scale. An additional stage, 86 , is added to the $\mathrm{BBCH}$ scale in CSCALES to correspond to the R5 dent stage on the Hanway scale. To further define the grain ripening phase for corn (Table 1), we included descriptions of corn kernel development based on milk-line changes (Afuakwa and Crookston, 1984; Crookston and Kurle, 1987).
Table 1. Correlation of the BBCH (Lancashire et al., 1991) and Hanway (Ritchie et al., 1986) developmental scales for corn used to convert between the scales in SCALES 2.

\begin{tabular}{|c|c|c|c|}
\hline \multicolumn{2}{|c|}{$\begin{array}{l}\text { BBCH } \\
\text { Stage } \dagger\end{array}$} & \multirow{2}{*}{$\begin{array}{l}\text { Hanway } \\
\text { Stage\& }\end{array}$} & \multirow[b]{2}{*}{ Stage description } \\
\hline 1 & 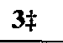 & & \\
\hline $\begin{array}{l}00 \\
01 \\
03 \\
05 \\
05 \\
06 \\
07 \\
09\end{array}$ & 0 & $\begin{array}{l}0 \\
\dot{5} \\
\dot{\mathbf{v E}}\end{array}$ & $\begin{array}{l}\text { Germination } \\
\text { dry seed } \\
\text { beginning of imbibition } \\
\text { imbibition complete } \\
\text { radicle emerged from seed } \\
\text { radicle elongated; root hairs visible } \\
\text { coleoptile emerged from seed } \\
\text { emergence (coleoptile penetrates soil) }\end{array}$ \\
\hline $\begin{array}{l}10 \\
11 \\
119\end{array}$ & $\begin{array}{l}\mathbf{0} \\
\dot{0} \\
\dot{0}\end{array}$ & $\begin{array}{l}\text { VE } \\
\text { V1 } \\
\text { VN } \\
\text { VN }\end{array}$ & $\begin{array}{l}\text { Seedling development } \\
\text { first leaf through coleoptile } \\
\text { first leaf unfolded (collared) } \\
N \text { th leaf unfolded ( } \leq 99 \text { for BBCH) } \\
\text { nine or more leaves unfolded ( } N \text { leaves unfolded) }\end{array}$ \\
\hline & $\begin{array}{l}30 \\
31 \\
32\end{array}$ & $\begin{array}{l}\mathbf{V N} \\
\dot{ }\end{array}$ & $\begin{array}{l}\text { Stem elongation } \\
\text { beginning of stem elongation } \\
\text { first node detectable } \\
\text { second node detectable }\end{array}$ \\
\hline & $\dot{39}$ & vi & nine or more nodes detectable \\
\hline & $\begin{array}{l}51 \\
53 \\
55 \\
59\end{array}$ & $\begin{array}{l}\mathbf{V N} \\
\dot{\mathbf{V T}}\end{array}$ & $\begin{array}{l}\text { Inflorescence emergence } \\
\text { beginning of tassel emergence } \\
\text { tip of tassel visible } \\
\text { middle of tassel begins to separate } \\
\text { tassel fully emerged and separated }\end{array}$ \\
\hline . & 61 & VT & $\begin{array}{l}\text { Anthesis } \\
\text { tip of ear possibly emerging from leaf sheath; } \\
\text { stamens in middle of tassel visible }\end{array}$ \\
\hline . & 63 & $\mathbf{R 1}$ & $\begin{array}{l}\text { silking; tips of stigmata visible; pollen shed may } \\
\text { begin }\end{array}$ \\
\hline - & 65 & . & $\begin{array}{l}\text { stigmata fully emerged; upper and lower parts } \\
\text { of tassel in flower }\end{array}$ \\
\hline & $\begin{array}{l}67 \\
69\end{array}$ & : & $\begin{array}{l}\text { stigmata drying; fowering completed } \\
\text { stigmata dry; end of flowering }\end{array}$ \\
\hline • & $\begin{array}{l}71 \\
73 \\
75\end{array}$ & $\begin{array}{l}\mathbf{R 2} \\
\dot{\mathbf{R 3}}\end{array}$ & $\begin{array}{l}\text { Development of grain } \\
\text { blister stage; } 16 \% \text { dry matter } \\
\text { early milk } \\
\text { milk stage; middle kernels milky, yellowish- } \\
\text { white; } 40 \% \text { dry matter } \\
\text { nearly all kernels have reached final volume }\end{array}$ \\
\hline - & $\begin{array}{l}83 \\
85\end{array}$ & $\begin{array}{l}\mathbf{R 3} \\
\mathbf{R 4}\end{array}$ & $\begin{array}{l}\text { Ripening } \\
\text { early dough; kernel soft; } \mathbf{4 0} \% \text { dry matter } \\
\text { dough; kernels yellowish to yellow; } 55 \% \text { dry } \\
\text { matter }\end{array}$ \\
\hline - & 86I & $\mathbf{R 5}$ & $\begin{array}{l}\text { dent stage; most kernels dented } \\
1 / 2 \text { milk stage }\end{array}$ \\
\hline & & & $1 / 4$ milk stage \\
\hline & 87 & R6 & $\begin{array}{l}\text { physiological maturity; black layer visible; } 60 \% \\
\text { dry matter }\end{array}$ \\
\hline . & 89 & . & fully ripe; kernels hard, shiny; $65 \%$ dry matter \\
\hline : & $\begin{array}{l}97 \\
99\end{array}$ & R6 & $\begin{array}{l}\text { Senescence } \\
\text { plant dead and collapsing } \\
\text { harvested product }\end{array}$ \\
\hline
\end{tabular}

$\dagger$ Although the BBCH stage is usually presented as a single value between 0 and 99, SCALES 2 uses two codes concurrently, in order to retain information about the number of leaves produced on the plant. After emergence, the first number on the BBCH scale is 10 plus the number of fully expanded leaves on the main stem; the maximum value is 19 . Note that main stem leaf appearance is not complete by the time stem elongation begins and continues until the tassel has emerged (VT).

\$ Note that the second number on the BBCH scale is not used for corn. Values of the third number on the BBCH scale ranging from 30 to 39 reflect the number of visible nodes on the main stem ( 0 to 9 or more). The plant may reach Stage 51 (beginning of tassel emergence) after fewer than 9 nodes have become visible, skipping intermediate values. $\$ \mathbf{N}$ refers to the number of unfolded leaves (leaf collar visible).

II The BBCH scale does not define a stage for 86. The Hanway R5 dent stage fits between the definitions for BBCH stages 85 and 87 . It is added for completeness along with the $1 / 2$ and $1 / 4$ milk stages.

Where the more species-specific scales (Hanway, Haun, Feekes, and ZCK) lack complete correspondence with the more general $\mathrm{BBCH}$ scale, we use the $\mathrm{BBCH}$ 
Table 2. Correlation of the BBCH (Lancashire et al., 1991), Zadoks-Chang-Konzak (Zadoks et al., 1974), Feekes (Large, 1954), and Haun (1973) developmental scales for small grains used to convert among the scales in SCALES 2.

\begin{tabular}{|c|c|c|c|c|c|c|c|c|}
\hline \multicolumn{3}{|c|}{ BBCH Stage } & \multicolumn{3}{|c|}{ Zadoks Stage } & \multirow{2}{*}{$\begin{array}{l}\text { Feekes } \\
\text { Stage }\end{array}$} & \multirow[b]{2}{*}{ Haun StageI } & \multirow[b]{2}{*}{ Stage description } \\
\hline $1 \dagger$ & $2 \ddagger$ & $3 \S$ & 1 & 2 & 3 & & & \\
\hline 00 & 0 & 0 & 00 & 0 & & 0,00 & 0.0 & Germination \\
\hline 01 & . & 政 & 01 & . & . & $\begin{array}{c}0.00 \\
.\end{array}$ & $\begin{array}{c}0.0 \\
.\end{array}$ & beginning of imbibition \\
\hline $\mathbf{0 3}$ & • & . & $\mathbf{0 3}$ & . & : & . & $\dot{.}$ & imbibition complete \\
\hline 05 & . & . & 05 & . & . & . & . & radicle emerged from seed \\
\hline 07 & . & . & 07 & . & . & $\cdot$ & & coleoptile emerged from seed \\
\hline \multirow[t]{2}{*}{09} & $\mathbf{0}$ & 0 & 09 & $\mathbf{0}$ & $\mathbf{0}$ & 0.00 & 0.0 & emergence \\
\hline & & & & & & & & Seedling development (growth of main stem) \\
\hline $\mathbf{1 0}$ & $\begin{array}{l}20 \\
20\end{array}$ & $\mathbf{0}$ & 10 & 20 & $\mathbf{0}$ & 1.00 & 0.x & first leaf through coleoptile \\
\hline $\mathbf{1 N}$ & . & 0 & $\mathbf{1 1}$ & 20 & $\mathbf{0}$ & $\mathbf{1 . 0 0}$ & $1 . x$ & $\begin{array}{l}\text { first leaf unfolded (collared) } \\
N \text { th leaf unfolded ( } N \leq 9 \text { for BBCH and Zadoks) }\end{array}$ \\
\hline \multirow{3}{*}{$\dot{19}$} & & 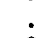 & & & $\cdot$ & ${ }^{\circ}$ & W & \\
\hline & 20 & $\mathbf{0}$ & 19 & 20 & $\mathbf{0}$ & 1.00 & N.x & nine or more leaves unfolded ( $N$ leaves unfolded) \\
\hline & & & & & & & & Tillering \\
\hline . & 21 & $\mathbf{0}$ & . & 21 & 0 & 2.00 & N.x & first tiller detectable \\
\hline . & 22 & . & . & 22 & . & • & • & second tiller detectable \\
\hline - & $\dot{0}$ & - & - & & - & - & - & $\cdots$. \\
\hline - & 29 & . & - & 29 & . & . & 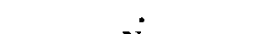 & nine or more tillers detectable \\
\hline • & 29 & $\mathbf{0}$ & - & 29 & $\mathbf{0}$ & 3.00 & N.x & tillering complete \\
\hline & & & & & & & & Stem elongation \\
\hline . & - & 30 & . & - & 30 & $\begin{array}{l}4.00 \\
5.00\end{array}$ & N.x & sheaths lengthening \\
\hline - & - & ii & - & - & $\dot{i}$ & $\begin{array}{l}5.00 \\
6.00\end{array}$ & • & pseudostem erect \\
\hline - & - & 31 & - & - & 31 & 6.00 & • & jointing (first node visible) \\
\hline - & - & 32 & - & - & 32 & $\mathbf{7 . 0 0}$ & . & second node visible, penultimate leaf visible \\
\hline - & - & $\dot{36}$ & $\cdot$ & - & $\dot{36}$ & - & $\cdot$ & ärth node visible \\
\hline • & • & 36 & • & • & 37 & 800 & $(\mathbf{F}-1) \mathbf{x}$ & $\begin{array}{l}\text { Sixth node visble } \\
\text { flag leaf visible. }\end{array}$ \\
\hline : & : & 39 & $\dot{5}$ & $\dot{:}$ & 39 & 9.00 & F.0 & $\begin{array}{l}\text { llag lear visible } \\
\text { flag leaf ligule visible }\end{array}$ \\
\hline & & & & & & & & Flag leaf extension \\
\hline - & . & 41 & . & . & 41 & 9.00 & $\mathbf{F}<\mathbf{H}<\mathbf{F}+\mathbf{1}$ & early boot; flag leaf sheath extending \\
\hline . & & 43 & . & . & 43 & 10.00 & $F+1<H<F+125$ & Booting \\
\hline : & : & 45 & : & : & 45 & 10.00 & $\mathbf{F}+\mathbf{1 . 2 5} \leq \mathbf{H}<\mathbf{F}+1.5$ & $\begin{array}{l}\text { mid-boot (just visibly swollen) } \\
\text { late boot (boots swollen) }\end{array}$ \\
\hline . & . & 47 & . & . & 47 & . & $\mathbf{F}+\mathbf{1 . 5} \leq \mathbf{H}<\mathbf{F}+\mathbf{1 . 7 5}$ & \\
\hline - & . & 49 & . & . & 49 & . & $\mathbf{F}+\mathbf{1 . 7 5} \leq \mathbf{H}<\mathbf{F}+\mathbf{2}$ & flag leaf sheath open; first awns visible \\
\hline & & & & & & & & Heading \\
\hline - & - & 51 & . & . & 51 & 10.10 & $\mathbf{F}+\mathbf{2} \leq \mathbf{H}<\mathbf{F}+\mathbf{2 . 3}$ & first spikelet visible \\
\hline . & . & $\mathbf{5 3}$ & . & . & 53 & 10.20 & $\mathbf{F}+\mathbf{2 . 3} \leq \mathbf{H}<\mathbf{F}+\mathbf{2 . 5}$ & $\mathbf{3 0} \%$ of spike emerged \\
\hline . & . & 55 & . & . & 55 & 10.30 & $\mathbf{F}+\mathbf{2 . 5} \leq \mathbf{H}<\mathbf{F}+\mathbf{2 . 7}$ & $50 \%$ emerged \\
\hline . & - & 57 & - & . & 57 & 10.40 & $\mathbf{F}+\mathbf{2 . 7} \leq \mathbf{H}<\mathbf{F}+\mathbf{3}$ & $70 \%$ emerged \\
\hline - & . & 59 & . & . & 59 & 10.50 & $\mathbf{F}+\mathbf{3} \leq \mathbf{H}<\mathbf{F}+\mathbf{4}$ & $\begin{array}{l}\text { Spike elongation (extension of peduncle) } \\
\text { spike fully emerged }\end{array}$ \\
\hline & & & & & & & & Anthesis \\
\hline - & - & 61 & - & - & 61 & 10.51 & $\mathbf{F}+4$ & beginning of anthesis \\
\hline . & . & 65 & . & . & 65 & 10.52 & . & anthesis half complete (to top of ear) \\
\hline . & . & 69 & . & . & 69 & 10.53 & . & anthesis over \\
\hline & & & & & & & & Development of grain \\
\hline . & . & 71 & . & . & 71 & 10.54 & $\mathbf{F}+4$ & kernel watery-ripe \\
\hline . & . & 73 & . & . & 73 & & . & early milk \\
\hline - & . & 75 & . & . & 75 & 11.10 & . & medium milk (milky ripe) \\
\hline - & • & 77 & • & . & 77 & . & - & late milk \\
\hline & & & & & & & & Ripening (dough development) \\
\hline - & - & 83 & • & - & $\mathbf{8 3}$ & & - & early dough \\
\hline - & - & 85 & - & - & 85 & 11.20 & . & soft dough, mealy ripe \\
\hline . & . & 87 & . & . & 87 & & . & hard dough \\
\hline - & . & 89 & . & . & 91 & 11.30 & . & kernel hard; difficult to divide \\
\hline & & & & & & & & Senescence \\
\hline - & - & 92 & - & - & 92 & & . & kernel hard \\
\hline - & - & 93 & • & - & 93 & 11.40 & . & ripe for cutting, kernel loosening in daytime \\
\hline - & . & 97 & . & . & 94 & • & . & straw dead and collapsing \\
\hline . & . & 99 & . & - & 99 & . & . & harvested product \\
\hline
\end{tabular}

$\uparrow$ Although the BBCH and ZCK stages are usually presented as a single value between 0 and 99, SCALES 2 uses three codes concurrently, in order to retain information about the number of leaves and tillers produced on the plant. After emergence, the first number on the BBCH and ZCK scales is 10 plus the number of fully expanded leaves on main stem; the maximum value is 19. Note that main stem leaf appearance is not complete by the time tillering begins and may extend into the early stem elongation phase.

¥ The second number on BBCH and ZCK scales is 20 plus the number of tillers on the plant; the maximum value is 29 . Note that tiller production may continue until the time of jointing, which is Feekes Stage 6, BBCH and ZCK Stage 31.

$\$$ Values of the third number on the BBCH and ZCK scales ranging from 30 to 36 reflect the number of visible nodes on main stem (0 to 6). The plant may reach Stage 37 after fewer than 6 nodes have become visible, skipping intermediate values.

If From emergence until the flag leaf is fully expanded, the Haun stage value is calculated as the number of fully expanded leaves $(N)$ on the main stem plus the relative development of youngest leaf on main stem. After the flag leaf is completely expanded, the exact Haun value lies within the range shown and is calculated from user's response to various questions about the progress of each stage. $H=$ Haun value; $F=$ leaf number of main stem flag leaf. 
scale descriptions. This is apparent in the percentages of dry matter in the grain presented in the correlation of the $\mathrm{BBCH}$ and Hanway scales in the grain ripening phase (Table 1).

The scientific goal of developing universally applicable crop scales conflicts with the programming goal of providing maximal error checking. We chose to make the SCALES 2 programs applicable over a wide variety of conditions, thus relying on the user to supply accurate inputs. As standardization of crop development scales progresses, and more crops and staging systems are added to computerized staging systems, error checking may become even more difficult to accomplish without restricting the user to common conditions.

As more crops and staging scales are included in scale conversion programs, it may be desirable to combine them into a single computer program. We chose not to do so, because the existing scales for corn and small grains are so different that the code diverged immediately after the user indicated the crop. Retaining both types of crops in a single computer program would result in more lengthy and confusing code with no gain in efficiency.

\section{Specifications, Documentation, and Availability}

SCALES 2 is written in ANSI standard Fortran 77. The program is designed for IBM-compatible microcomputers running DOS version 3.3 or greater. ${ }^{2}$ A hard disk and math coprocessor are not required.

SCALES 2 is available from the Soil and Water Conservation Research Unit, 119 Keim Hall, University of Nebraska, Lincoln, NE, 68583-0934. The source code, executable program, and documentation are distributed on 3.5-inch diskettes.

\section{References}

Afuakwa, J.J., and R.K. Crookston. 1984. Using the kernel milk line to visually monitor grain maturity in maize. Crop Sci. 24:687-691.

Bauer, A., D. Smika, and A. Black. 1983. Correlation of five wheat growth stage scales used in the Great Plains. Publ. AAT-NC-7. USDA-ARS, Peoria, IL.

Crookston, R.K., and J.E. Kurle. 1987. Corn kernel milk line: Use it as a key for harvesting silage. Crops Soils 39:14-15.

Harrell, D.M., W.W. Wilhelm, and G.S. McMaster. 1993. SCALES: A computer program to convert among three developmental stage scales for wheat. Agron. J. 85:758-763.

Haun, J.R. 1973. Visual quantification of wheat development. Agron. J. 65:116-119.

Lancashire, P.D., H. Bleiholder, T. van den Boom, P. Langeluddeke, R. Stauss, E. Weber, and A. Witzenberger. 1991. A uniform decimal code for growth stages of crops and weeds. Ann. Appl. Biol. 119:561-601.

Large, E.C. 1954. Growth stages in cereals. Plant Pathol. 3:128-129.

Ritchie, S.W., J.J. Hanway, and G.O. Benson. 1986. How a corn plant develops. Rev. ed. Iowa State Univ. Coop. Ext. Serv. Spec. Rep. 48.

Zadoks, J.C., T.T. Chang, and C.F. Konzak. 1974. A decimal code for the growth stages of cereals. Weed Res. 14:415-421.

\footnotetext{
${ }^{2}$ Mention of a trademark or proprietary product does not constitute an endorsement by the authors, the University of Nebraska, or the USDA.
} 